\title{
AVALIAÇÃO SOBRE O CONHECIMENTO DO LASER ENTRE ALUNOS E PROFESSORES DO CURSO DE ODONTOLOGIA DA ESCOLA BAHIANA DE MEDICINA E SAÚDE PUBLICA, SALVADOR-BA
}

\author{
Lívia Prates Soares Zerbinati ${ }^{\alpha}$ \\ Mariana de Assis Oliveira Pinto ${ }^{b}$ \\ Roberta Lima Santos ${ }^{b}$ \\ Raissa de Castro Silva Lacerdac
}

\begin{abstract}
Resumo
Os aparelhos de laser, cirúrgicos ou terapêuticos, vêm sendo extensivamente utilizados na área Odontológica, o que traz, por consequência, vantagens aos pacientes. Com comprimentos de onda, potência e frequência diferentes, os lasers mostram diversas aplicabilidades. Entretanto, tanto o paciente quanto o profissional de saúde ainda não possuem o conhecimento do adequado do seu uso, podendo ocasionar um resultado abaixo do esperado ou até mesmo algum dano tecidual. O presente trabalho objetiva realizar uma avaliação sobre o conhecimento da laserterapia entre os professores e alunos de Odontologia da Escola Bahiana de Medicina e Saúde Pública. Este estudo populacional do tipo seccional foi desenvolvido através do instrumento de análise de questionário, composto de questões fechadas, com a finalidade de avaliar o grau de conhecimento sobre as características e aplicações do laser nas suas diferentes especialidades Odontológicas. Em nossos resultados foi possível observar que na população da Instituição estudada o número de alunos foi de 64 respondentes e 25 professores respondentes, do total de 528 alunos e 76 professores presentes na instituição. Um baixo percentual de alunos do curso de Odontologia demonstrou ter conhecimento sobre a laserterapia, o qual somente $28,6 \%$ do alunos participantes sabiam o significado da palavra laser e apenas $11,7 \%$ dos alunos tiveram alguma aula sobre o assunto. Também verificou-se que existe pouca transmissão de informação no curso de Odontologia, pois $85,7 \%$ dos alunos relataram que não tiveram qualquer aula sobre este recurso na graduação. Com relação aos professores, já profissionais da área de saúde, houve também um baixo nível de conhecimento sobre o laser e seus recursos, apenas $1 \%$ dos professores disseram possuir este durante a graduação, enquanto $36 \%$ diz ter adquirido esse conhecimento na pós-graduação. Quanto à realização de um curso direcionado ao laser,
\end{abstract}

a. Doutora em Cirurgia e Traumatologia Bucomaxilofacial, Mestre em Cirurgia e Traumatologia, Bucomaxilofacial, Especialista em Cirurgia e Traumatologia Bucomaxilofacial, Professora do Curso de Odontologia da UNIME e Professora do Curso de Odontologia da Escola Bahiana de Medicina e Saúde Publica. raissacslacerda@hotmail.com

b. Graduada em Odontologia pela Escola Bahiana de Medicina e Saúde Publica

c. Graduanda em Odontologia pela Escola Bahiana de Medicina e Saúde Publica 
apenas $16 \%$ relata ter buscado, porém a minoria com $80 \%$ diz que não. Estes resultados demonstram a necessidade de implementação da literatura e transmissão de conhecimento sobre o laser, tanto na graduação em Odontologia quanto na pós-graduação, já que este recurso está tendo resultados positivos no consultório odontológico e tem sido cada vez mais implementado no cotidiano das clinicas.

Palavras-chave: Laser. Aplicabilidade. Conhecimento.

\title{
EVALUATION OF THE KNOWLEDGE OF LASER BETWEEN STUDENTS AND TEACHERS OF COURSE DENTISTRY
}

\begin{abstract}
Summary
Laser equipment, surgical or therapeutic, have been extensively used in the dental area, which has therefore benefits to the patients. Of wavelength, power and frequency different lasers show many applicabilities. However, both patient and health professionals still lack adequate knowledge of its use, and may cause a lower than expected results or even damage tissue. This work aims to conduct an assessment on the knowledge of the laser between teachers and students of Dentistry on Escola Bahiana de Medicina e Saúde Pública. This sectional population study of the instrument was developed through analysis of a questionnaire composed of closed questions, in order to assess the degree of knowledge about the characteristics and applications of laser in its different specialties Dental. In our results we observed that the population of the institution studied the number of students was 64 respondents and 25 respondents teachers, a low percentage of students of Dentistry has demonstrated knowledge of the laser. It was observed that there is little reporting on this subject in graduation. With regard to teachers, as professionals in health, there was also a low level of knowledge on the Laser and its resources. In our results we observed that the population of the institution studied the number of students was 64 respondents 25 teachers respondents from the total of 528 students and 76 teachers attending the institution. A low percentage of students of Dentistry has demonstrated knowledge about laser therapy, which only $28.6 \%$ of the participating students knew the meaning of the word laser and only $11.7 \%$ of students had a lesson on the subject. Also it was found that there is little transmission of information in the course of Dentistry because $85.7 \%$ of students reported that they had no class on this feature graduation. With respect to teachers, as professionals in the health field, there was also a low level of knowledge about the laser and its resources, only $1 \%$ of teachers have said this during graduation, while $36 \%$ said to have acquired this knowledge in postgraduate. Regarding offering a course directed to the laser, only $16 \%$ reported having sought, but the minority with $80 \%$ says no. These results demonstrate the need to implement the transmission of knowledge and literature on the laser, both in undergraduate and in Dentistry graduate, since this feature is having positive results in the dental office and has been increasingly implemented in the daily clinical.
\end{abstract}

Keywords: Laser. Applicability. Knowledge. 


\section{INTRODUÇÃO}

A palavra LASER é o acrônimo de Ligth Amplification by Stimulated Emission of Radiation (Amplificação da Luz por Emissão Estimulada de Radiação) e é uma forma de radiação eletromagnética que se transforma em energia luminosa. O que faz o laser ser diferente da luz comum são suas características peculiares e importantes, tais como: constituir-se em uma fonte monocromática que pode atingir alta intensidade, ser coerente e altamente concentrada, assim como unidirecional. (1)

A radiação laser é um feixe de luz altamente focado que pode penetrar em camadas mais profundas e estimular os fotorreceptores de tecidos vivos (pele ou mucosa), estes são capazes de absorver fótons de determinados comprimentos de onda provocando uma transformação na atividade funcional e metabólica das células com resultados fotoquímico, analgésico, antiinflamatório e de bioestimulação. ${ }^{(2)}$

Os aparelhos de laser são nomeados de acordo com as substância radioativas que eles contêm. Essas substâncias podem estar na forma de cristais sólidos, ou na forma de semicondutores diodos. São classificados, também, pela potência, dividindo-se em laser de alta potência (cirúrgico) ou de baixa potência (terapêutico). O primeiro produz efeito térmi$\mathrm{co}$, tem potência superior a $500 \mathrm{~mW}$ (miliwatts) e é largamente empregado em cirurgias para coagular, seccionar ou vaporizar tecidos, sendo os principais de Rubi, CO2, Er:YAG, Ho:YAG, e Nd:YAG. ${ }^{(3)}$

Os primeiros laseres foram rapidamente introduzidos na Medicina, particularmente na cirurgia, utilizando-se de duas propriedades fototérmicas e fotoablativas por serem de alta potência. Posteriormente foi possível observar efeitos não térmicos benéficos quando aplicado em baixa intensidade. (4)

Os efeitos terapêuticos obtidos são: antiinflamatório, analgésico e reparação tecidual. É uma ajuda importante à prática profissional em associação com quase todas as especialidades odontológicas. O aumento substancial do interesse pela terapia tem sido notado em círculos científicos, devido ao significante número de resultados satisfatórios na sua mais diversa aplicabilidade. ${ }^{(5)}$

Nos diversos ramos das ciências de saúde, o laser tem várias aplicações. Começou a ser utilizado no processo de regeneração e recuperação funcional de lesões periféricas na década de 80 , havendo vários relatos sobre os resultados obtidos. ${ }^{(3)}$

A laserterapia é utilizada para o tratamento de diversas patologias, e um dos seus principais objetivos é normalizar o processo de reparação tecidual. O laser atua na pele aumentando a migração de fibroblastos e consequente formação de colágeno, promovidos pela vasodilatação, estimulando a síntese de DNA, e promovendo o aumento da atividade das células epiteliais basais. Desta forma este recurso favorece a cicatrização de feridas cutâneas. ${ }^{\left({ }^{(6)}\right.}$

A resposta primária à laserterapia ocorre na área de irradiação, mas uma resposta secundária, de natureza sistêmica, é suposta, devido à rede de transporte corporal dos fotoprodutos mediados pela laserterapia no sangue e no sistema linfático. Acredita-se que esses fotoprodutos, incluindo prostaglandinas e endorfinas, e seus efeitos, persistam por várias horas ou semanas. (7)

Especificamente na odontologia vem sendo amplamente difundido, porém nem sempre corretamente utilizado, pois o conhecimento básico de seu funcionamento ainda é muito deficiente pelos profissionais, principalmente aqueles que não foram especificamente treinados nesta área. ${ }^{(2)}$

A laserterapia é bastante eficaz no tratamento da hipersensibilidade dental que está associada a uma dor aguda, súbita e de curta duração. A hipersensibilidade pode ocorrer durante ou após a restauração dental, pela retração da gengiva, e após o clareamento dental. Também ajuda a diminuir o desconforto do paciente no momento da aplicação da anestesia, visto que pode ser utilizado como pré-anestésico. O laser promove aumento da microcirculação e, desta forma, ajuda na absorção do anestésico, nos casos de pacientes com dificuldade para serem anestesiados. ${ }^{(8)}$ 
Os lasers de Nd:YAG e Er:YAG estão sendo usados em Endodontia para a esterilização de canais infectados, na fusão apical e na obliteração de canais. O correto preparo ou modelagem dos canais radiculares é de fundamental importância na terapêutica endodôntica. $A$ instrumentação realizada com laser melhora a limpeza, remove o smear layer, promovendo também selamento dos canalículos dentinários; além disso, proporciona paredes dentinárias lisas e uniformes em menor tempo que a instrumentação convencional. ${ }^{(9)}$

Dentre os benefícios do laser para implantodontia, observa-se: a diminuição da dor pós-operatória, menor edema e inflamação, cicatrização óssea mais acelerada, levando a um menor tempo de espera pós-cirúrgico (enxertia óssea, implante, manipulação de tecido mole), mucosa integra e de meIhor qualidade em menor tempo de cicatrização, na terapêutica em parestesias, como coadjuvante no tratamento de peri-implantite. ${ }^{(10,11)}$

Diante do número crescente de aplicações clínicas do laser na Odontologia e de tantos parâmetros a serem observados para termos sucesso nas aplicações clínicas e do comprovado benefício no metabolismo em tecidos vivos, torna-se necessário um conhecimento adequado a respeito das bases físicas e de suas aplicações clínicas. Como se trata de uma modalidade relativamente recente na clínica diária dos cirurgiões dentistas é necessário que seja correntemente divulgado e ensinado em faculdades de cursos de ensino superior. Por tanto, esta pesquisa tem o intuito de avaliar o conhecimento sobre lasers e o impacto do mesmo na postura e atividades clínicas do aluno e professor de Odontologia dentista nos dias atuais, a fim de identificar as necessidades de uma melhor divulgação desta ciência e atualização dos currículos acadêmicos. ${ }^{(14)}$

\section{METODOLOGIA}

Após aprovação do projeto pelo comitê de ética da FBDC (Fundação Bahiana para Desenvolvimento das Ciências), foram aplicados questionários anônimos e sigilosos em que o aluno e professor de
Odontologia não foram identificados (Apêndices C e D). Estes questionários visam colher informações pessoais, gerais e específicas sobre os aspectos clínicos, científicos, psico-emocionais e socioeconômicos dos participantes. Além dos questionários, o pesquisado assinou um termo de consentimento livre e esclarecido fornecido e lido durante a pesquisa (Apêndice A).

O questionário usado tem como composição questões fechadas as quais abordam desde o conhecimento sobre laser, sua aplicabilidade e os tipos disponíveis para uso ate conhecimento no que se refere a estudo sobre o tema, visando a necessidade avaliar o conhecimento dos participantes da pesquisa sobre a laserterapia, a composição do laser e sua aplicabilidade na Odontologia. ${ }^{(14)}$

Para esta pesquisa foram aplicados 77 questionários para o corpo discente do curso de Odontologia da Faculdade Bahiana de Medicina e Saúde Pública e 25 questionários para o corpo docente da mesma instituição.

O questionário foi aplicado por pesquisadores devidamente treinados para a sua aplicação e com embasamento teórico sobre os tópicos de laser na Odontologia.

Foi aplicado questionário direcionado aos professores de Odontologia, pois estes são profissionais responsáveis pela transmissão de conhecimento de forma geral. Os Professores de todas as diferentes disciplinas foram solicitados a responder, já que o laser tem aplicabilidade em varias especialidades. Nesta instituição possuem 76 professores no curso de Odontologia de todos os semestres.

O questionário direcionado aos alunos foi aplicado em todos os semestres do curso de graduação, sendo que estes possuem 528 alunos no total de todos os semestres.

Os dados foram analisados através de análise estatística descritiva utilizando o Microsoft Excel pelas pesquisadoras responsáveis.

Este trabalho de pesquisa possui o número de protocolo 13/2012 e o número do CAAE é 02384112.4 .0000 .5544 


\section{RESULTADOS}

Apesar da amostra disponível na instituição ser maior do que a usada na pesquisa, a coleta de informações foi de caráter convencional, o qual participava da pesquisa candidatos dispostos a responder o questionário por livre interesse em contribuir.

Foram obtidos 77 questionários respondidos por alunos, dentre os quais $59,7 \%$ (46) são do sexo feminino e 40,3\% (30) do sexo masculino. Quanto à idade, $72,2 \%$ (56) possuem entre 17 a 34 anos e $9 \%$ (7) de 25 a 32 anos. Em relação ao estado civil, 87\% (67) são solteiros e apenas 5,2\% (4) são casados.

Dos alunos participantes da pesquisa, os que pretendem fazer especialização, 6,5\% (5) não sabem que área irão escolher. Já aqueles que irão seguir uma especialização logo após formados, 15,6\% (12) pretendem fazer Cirugia Buco-Maxilo-Facial, 14,3\% (11) irão fazer Endodontia, Ortodontia e Implante, 13\% (10) querem fazer Prótese, 5,2\% (4) para Periodontia e Dentística, 3,9\% (3) para Odontopediatria e por fim, 1,3\% (1) quer Saúde Coletiva.

A grande maioria dos estudantes, 77,9\% (60) declarou já ter participado de congressos e 14,3\% (11) afirmam nunca terem ido a congressos.

Em termos de conhecimento relacionado ao laser, $85,7 \%$ (66) dos alunos dizem conhecer o laser. Já $13 \%$ (10) dizem que não tem esse conhecimento. Sendo que daqueles que possuem o conhecimento, $10,4 \%$ (8), dizem possuir o aparelho de laser particular, sendo 7 (sete) terapêutico e 1 (um) cirúrgico, e 96,9\% (62) não possuem o aparelho.

É importante ressaltar o papel das Instituições de Ensino de Saúde em relação aos recursos utilizados para promover saúde. Sendo assim, 41,5\% (32) dizem que a Faculdade Bahiana de Medicina e Saúde Pública possui o aparelho de laser, dentre eles 2,6\% (2) são cirúrgicos e 31,2\% (24) são terapêuticos, outros $9 \%$ (7) dizem que esta não possui o aparelho e $48 \%$ (37) não sabem informar.
Atualmente, com o grande avanço da técnica de laserterapia, é fundamental que se conheça bem os seus princípios e atuações, porém, nesse estudo, verificou-se que apenas $24,7 \%$ (19) dos alunos tem acesso ao laser e $74 \%$ (57) não tem acesso ao mesmo.

Procurando saber o real significado da palavra "laser", foi visto que a maioria, $28,6 \%$ (22) acertaram respondendo que o laser é uma Amplificação da Luz por Emissão Estimulada de Radiação (Gráfico 1).

O conhecimento na graduação é um processo de transmissão de informação através do qual o aluno fica apto a entender os conceitos e mecanismos utilizados para cada assunto. Nesta pesquisa, observou-se que apenas $11,7 \%$ (9) dos alunos tiveram alguma aula sobre o laser e 85,7\% (66) não tiveram qualquer aula sobre este recurso na graduação. Além disso, foi questionado quanto à realização de curso direcionado ao laser e apenas 2,6\% (2) dizem ter feito e 92,2\% (1) não fizeram algum curso deste. Houve o interesse em realizar um curso de laserterapia apenas com $63,6 \%$ (49) dos alunos e $33,8 \%$ (26) não mostram interesse neste curso.

A grande maioria dos estudantes, $80,5 \%$ (62) dizem que não tiveram acesso algum a bibliografia relacionada ao laser e apenas $16,9 \%$ (13) afirmam que sim. Dentre estes, $13 \%$ (10) dizem que foi através de periódicos e 3,9\% (3) através de livros.

Com relação ao conhecimento sobre a diferença entre o laser cirúrgico e o laser terapêutico, 15,6\% (12) dos alunos dizem que tem esse conhecimento, e a maioria afirma que não sabe diferenciá-lo $83 \%$ (64). Quando questionados sobre as normas de Biossegurança para utilização do laser, 14,3\% (11) afirmam ter esse conhecimento, enquanto que $79,2 \%$ (61) dizem que não.

O tipo de indicação para situações clínicas do laser terapêutico mais relatado foi o Clareamento dentário com $74 \%$ (57), conforme pode ser visto no Gráfico 2. Em relação a indicação quanto ao laser cirúrgico o mais considerado foi Carcinoma com $35 \%$ (27) podendo ser visto no Gráfico 3. 
Gráfico 1. Distribuição do percentual de alunos em relação às respostas à pergunta "O laser é" para alunos. Para as respostas referente as letras a opção "a" foi a resposta de escolha para 7\% dos participantes; "b" foi resposta para $24 \%$ dos participantes; "c" para $15 \%$ dos participantes; "d" foi a resposta de escolha para $21 \%$ dos participantes e "e" sendo esta a resposta correta foi a opção de escolha para $33 \%$ dos participantes da pesquisa

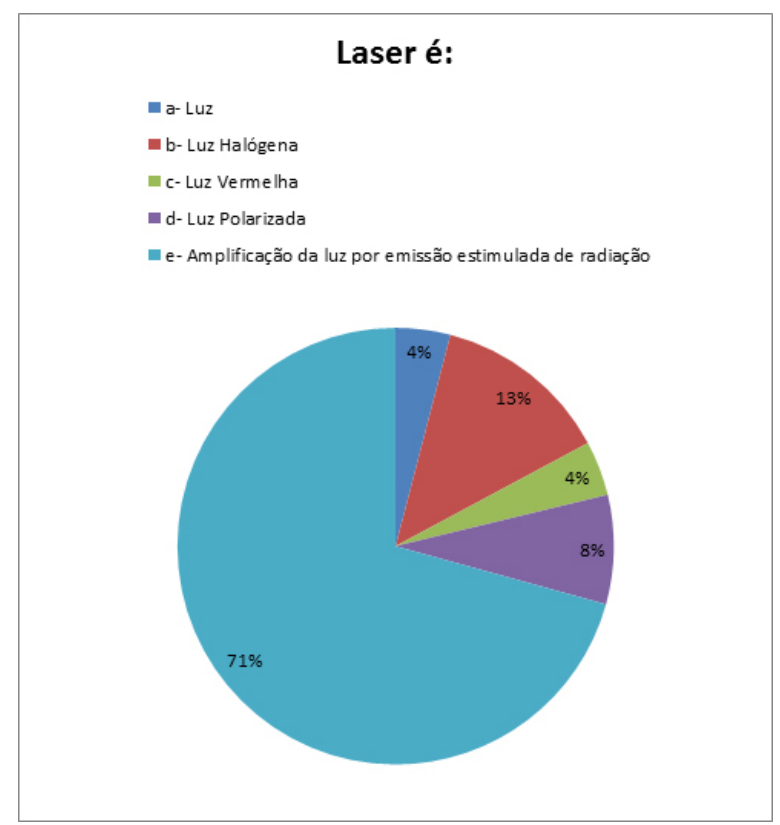

Gráfico 2. Distribuição do percentual de alunos em relação às respostas sobre indicação clínica do laser

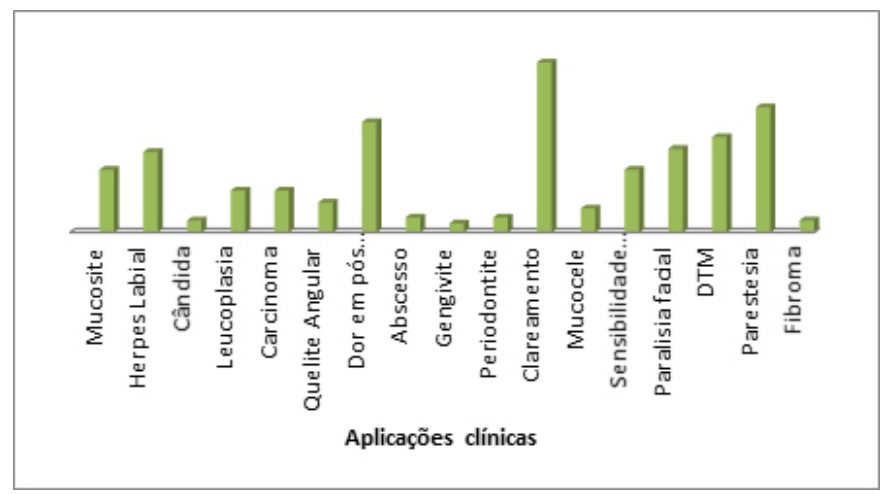

Gráfico 3. Distribuição do percentual de alunos em relação às respostas sobre indicação do laser cirúrgico

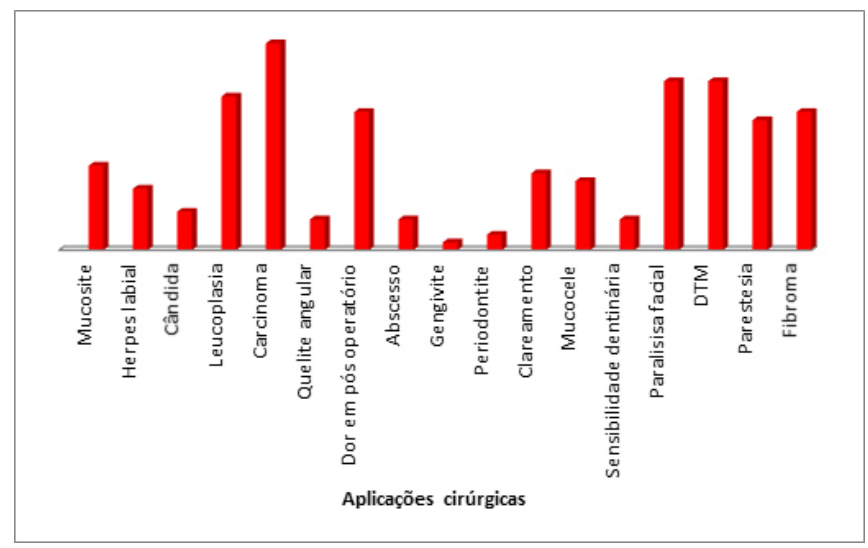


Em tratando-se do uso do laser em pacientes grávidas, 9\% (7) afirmam que é utilizado nesse tipo de paciente, 16,9\% (13) dizem que não e 70,1\% (54) não sabem se pode ser aplicado. Já em relação ao uso do laser em pacientes com marcapasso, $9 \%$ (7) dizem que pode ser utilizado, $15,6 \%$ (12) não pode e a maioria, 68,8\% (53) afirmam que não sabem.

Foram respondidos também, 25 questionários com professores do curso de Odontologia, sendo que $60 \%$ representam professores com idade en tre 27 a 40 anos e $32 \%$ de 44 a 65 anos. Em relação ao sexo, $32 \%$ corresponde a mulheres e $64 \%$ a homens. Quanto ao tipo de professor, 4\% (1) diz ser professor substituto e $92 \%$ (23) professor efetivo.

Quanto à disciplina ensinada, 24,7\% (19) dos professores dizem que lecionam na clínica cirúrgica e $10,4 \%$ (8) afirmam que ensinam no laboratório. Dentre estes professores, $32 \%(8)$ ensinam somente na Bahiana e $64 \%$ (16) ensinam em outras instituições. Quanto à média de alunos ensinados por semestre, $84 \%$ (21) dos professores ensinam entre 12 a 100 alunos e $16 \%$ (4) destes ensinam em uma média de 120 a 300 alunos por semestre.

Quando questionado sobre o conceito do laser, a maioria com $88 \%$ (22) dizem saber o significado. Além disso, 16\% (4) dos professores afirmam que possuem o laser, dentre os quais todos são cirúrgicos e nenhum terapêutico. $80 \%$ (20) dos professores dizem não possuir o aparelho.

Sobre a existência do laser na Instituição de Ensino Superior, $40 \%$ (10) dizem que sim, os quais $4 \%$ (1) cirúrgicos e $48 \%$ (12) terapêuticos, $24 \%$ (6) afirmam que a Instituição não possui e $32 \%$ (8) não sabem.

Atualmente, muitos profissionais da área de Odontologia utilizam o laser em seus consultórios como meio terapêutico. Sendo assim, foi questionado o acesso do professor ao laser na sua vida profissional e $12 \%$ (3) dizem que sim e $64 \%$ (16) afirmam que não tem acesso. Quanto ao significado da palavra laser, a maioria $71 \%$ (16) respondeu Amplificação da Luz por emissão estimulada de radiação (Gráfico 4).

Grafico 4. Distribuição do percentual de resposta em relação à pergunta "O laser é" para os professores. Para as respostas referente as letras a opção "a" foi a resposta de escolha para 4\% dos participantes; "b" foi resposta para 13\% dos participantes; "c" para $4 \%$ dos participantes; "d" foi a resposta de escolha para $8 \%$ dos participantes e "e" sendo esta a resposta correta foi a opção de escolha para $71 \%$ dos participantes da pesquisa

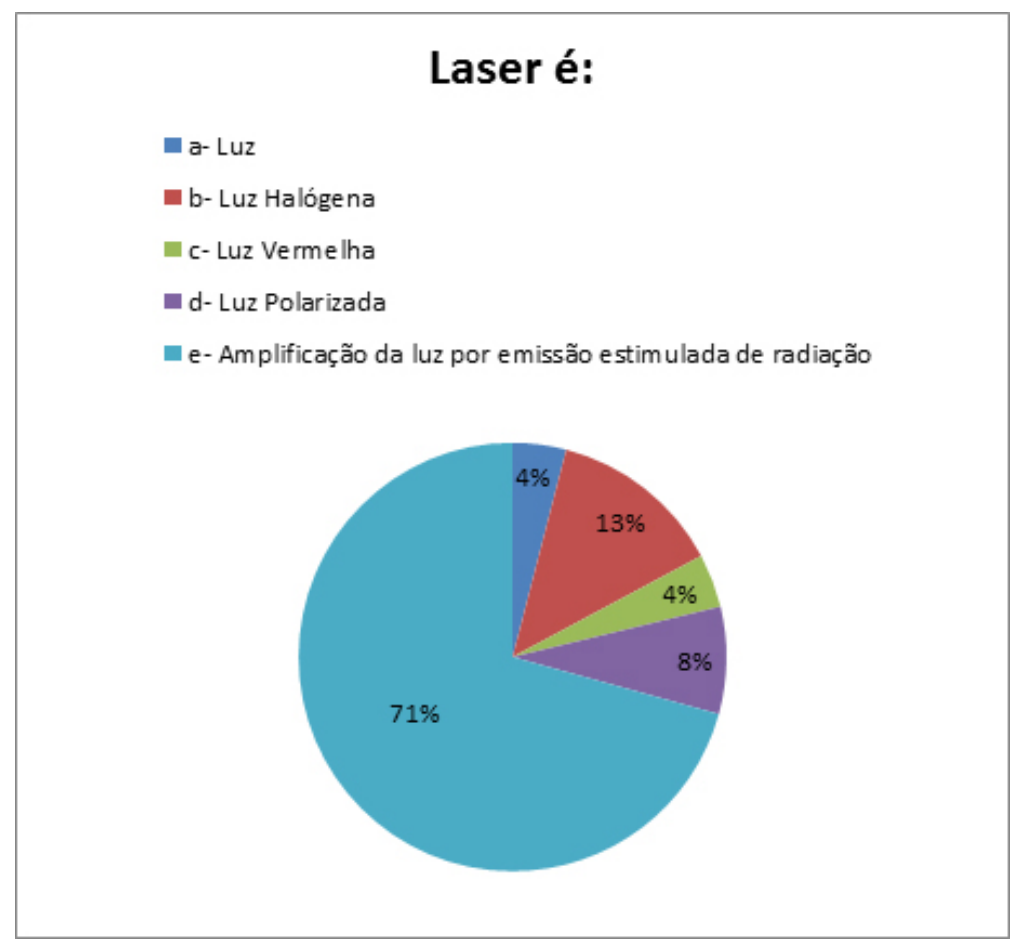


Em relação ao conhecimento do laser durante a graduação, apenas 1\% (4) dos professores disseram possuir este, enquanto que $88 \%$ (22) diz que não. Sobre adquirir esse conhecimento na pós-graduação, 36\% (9) diz que sim e 60\% (15) diz que não teve acesso durante esse período. Quanto à realização de um curso direcionado ao laser, apenas $16 \%$ (4) diz que tomou, porém a minoria com $80 \%$ (20) diz que não.

Do total dos professores participantes, $76 \%$ (19) dizem que tiveram acesso a bibliografia, dentre eles $72 \%$ (18) por periódicos e $20 \%$ (5) através de livros e outros $20 \%$ afirmam que não tiveram acesso a bibliografia com relação ao laser. Quanto ao conhecimento da diferença entre o laser cirúrgico e terapêutico, $16 \%$ (4) dizem que sabem e $76 \%$ (19) afirmam que não possuem esse conhecimento. Foi questionado também sobre as normas de Biossegurança na aplicação dos raios do laser e a maioria, $52 \%$ (13) não tem esse conhecimento e apenas 44\% (11) possuem este.

As diferentes indicações da aplicação laser na clínica demonstraram que o clareamento dental com $76 \%$ (19) foi a maioria neste caso, seguida de sensibilidade dentária com $72 \%$ (18), dentre outras, podendo ser avaliadas no Gráfico 5 . Em relação às indicações do laser cirúrgico, a maioria dos professores afirmou que o fibroma com 44\% (11) é a aplicação mais indicada. Gráfico 6 .

Gráfico 5. Distribuição do percentual de professores em relação às respostas sobre indicação clínica do laser

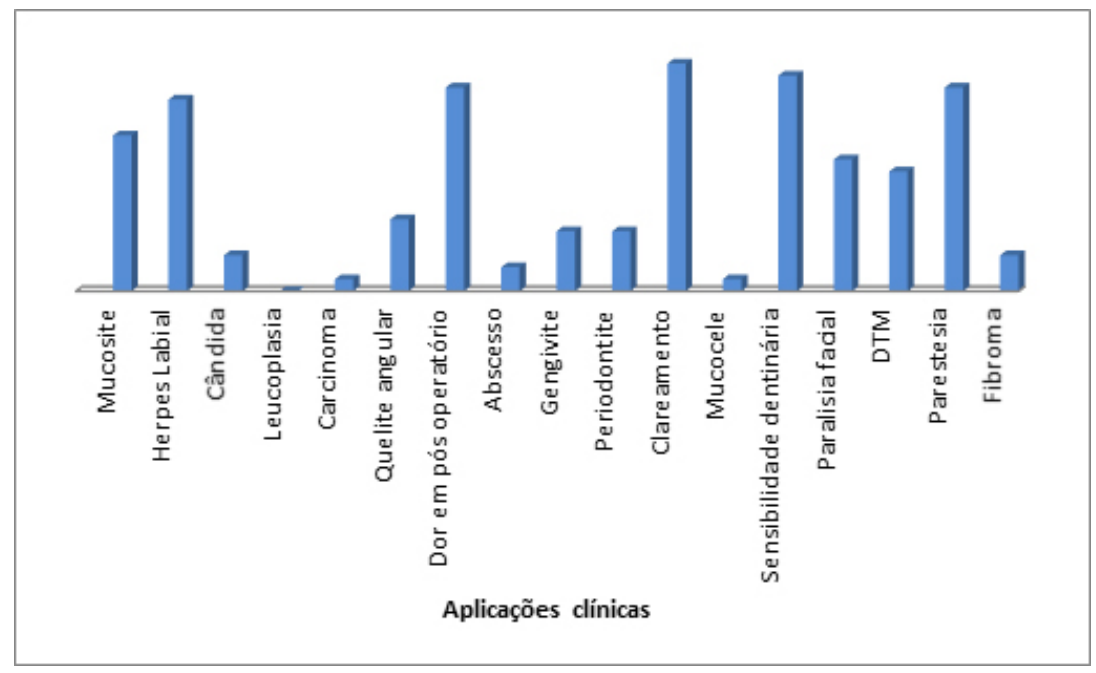

Gráfico 6. Distribuição do percentual de professores em relação às respostas sobre indicação cirúrgica do laser

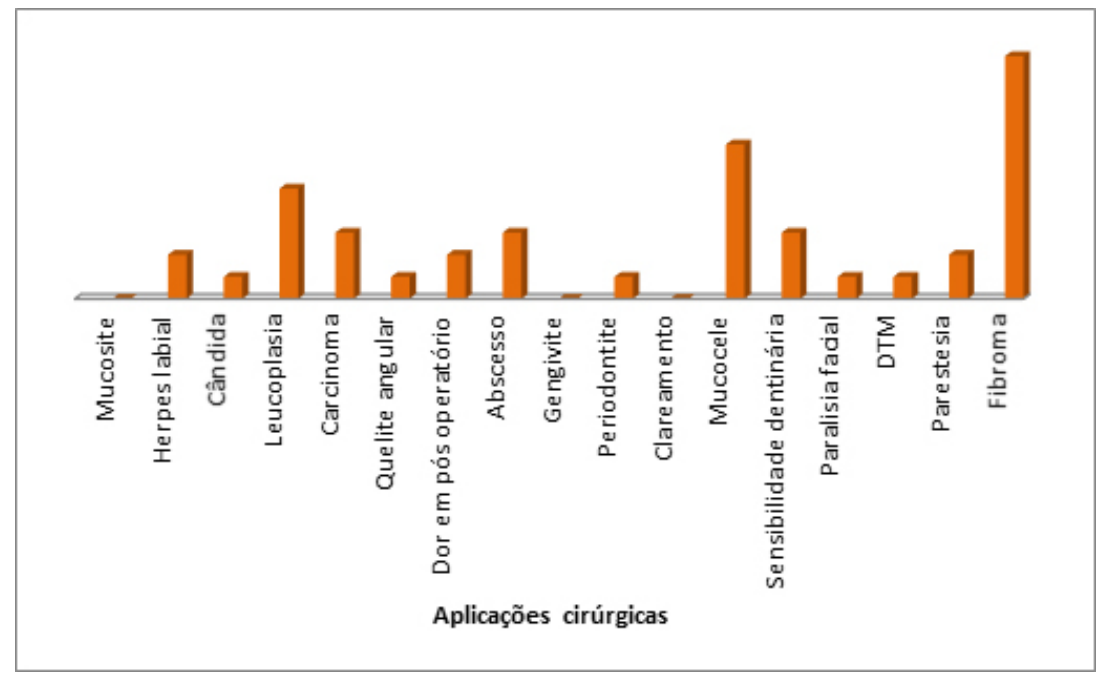


Quando foi questionado o uso da laserterapia em mulheres grávidas, $48 \%$ (12) dos professores dizem não saber se é permitido, 32\% (8) afirmam que pode ser usado o laser em grávidas e apenas 4\% (1) diz que não. Em relação ao uso do laser em pacientes portadores de marcapasso, 36\% (9) dos professores dizem que é permitido, $12 \%$ (3) diz que não e a maioria com 40\% (10) não sabem afirmar.

Foi questionado ao final, se o professor era usuário do laser e apenas $44 \%$ (11) sim. Dentre esses, um único (4\%) professor diz que o laser mudou sua conduta clínica. Foi questionado também, quais desses professores faziam clareamento no consultório e $20 \%$ (5) dizem que sim. O uso do laser em cirurgias estava em questão e apenas $8 \%$ (2) dizem que o laser é usado para fazer cirurgias e $32 \%$ (8) afirmam que não.

\section{DISCUSSÃO}

A maioria das queixas apresentadas pelos pacientes na Odontologia, frequentemente, esta relacionada à dor e inflamação. Em função disso, fica claro que a energia a laser é uma importante ferramenta, não só como coadjuvante do tratamento convencional, mas ele pode consistir na forma terapêutica por si só.

A tendência da Odontologia é a incorporação de métodos menos invasivos com a finalidade de minimizar a dor e desconforto durante e após as intervenções Odontológicas. Por isso, acredita-se que a laserterapia seja uma excelente opção de tratamento, já que apresenta efeitos benéficos para os tecidos irradiados. ${ }^{(14)}$

Atualmente, a laserterapia é considerada um tipo de procedimento terapêutico seguro, com indicações e contra-indicações bem determinadas. As razões para esse fato são: experiências clínicas positivas, investigações científicas das alterações teciduais que ela promove, e acima de tudo o meIhor entendimento do seu mecanismo de ação.

Neste trabalho foi demonstrado que os professores do curso de Odontologia possuem o conhe- cimento básico sobre o laser, porém não sabem a fundo suas indicações e contra indicações. Em relação aos alunos, estes não possuem o conhecimento sobre o laser, nem das suas aplicações. ${ }^{(15)}$

Com relação às normas de segurança, os aparelhos laser são classificados quanto as espectro eletromagnético e seus riscos em provocar lesões oculares. Portanto, torna-se indispensável à utilização de óculos de proteção pelo profissional, auxiliar e paciente. Na presente pesquisa foi constatado que poucos alunos, apenas $14 \%$ destes, tem o conhecimento sobre as normas de proteção utilizadas para a laserterapia. E mais da metade dos professores questionados também não conhecem as normas de biossegurança em relação ao laser. ${ }^{(14)}$

A radiação laser, utilizada com comprimentos de onda terapêuticos preconizados até o momento, não possui efeitos mutagênicos e pode ser usada repetidamente, sem riscos. O uso da radiação laser não é, ao que se pensa, contra-indicada em pacientes grávidas, portadores de marca-passo, nem causa interferência nos equipamentos de monitoração. ${ }^{(8)}$ Nota-se nos dados da pesquisa deficiente conhecimento quanto o uso nesses tipos específicos de pacientes. Quando questionados aos alunos uso do laser em pacientes grávidas, $9 \%$ afirmam que é utilizado nesse tipo de paciente, $16,9 \%$ dizem que não e mais da metade não sabem se pode ser aplicado. Já em relação ao uso do laser em pacientes com marcapasso, $9 \%$ dizem que pode ser utilizado, $15,6 \%$ não pode e a maioria afirmam que não sabem.

Observa-se que não é uma deficiência somente para os alunos pois quando questionado o uso da laserterapia em mulheres grávidas, $48 \%$ dos professores dizem não saber se é permitido, 32\% afirmam que pode ser usado o laser em grávidas e apenas um diz que não. Em relação ao uso do laser em pacientes portadores de marcapasso, $36 \%$ dos professores dizem que é permitido, $12 \%$ diz que não e a maioria não sabem afirmar.

Novas matérias foram propostas pelo projeto de "Diretrizes Curriculares" e pelo "Instrumento de verificações das condições de oferta dos cursos de 
graduação em Odontologia", algumas delas são: terceira idade, clinica do bêbe, pacientes especiais, bioética, biossegurança, língua estrangeira (instrumentais) e laser. ${ }^{(15)}$ Portanto a introdução da disciplina laser durante a graduação em Odontologia, proporciona a mudança no quadro encontrado na pesquisa, o qual $28,6 \%$ do alunos participantes sabiam o significado da palavra laser e apenas $11,7 \%$ dos alunos tiveram alguma aula sobre o laser e $85,7 \%$ não tiveram qualquer aula sobre este recurso na graduação.

A implementação do estudo sobre laser na graduação poderia estimular mais profissionais buscarem especializar-se na área, tendo em vista que nos achados da pesquisa apenas 1\% dos professores disseram possuir conhecimento sobre laser adquirido durante a graduação, enquanto $36 \%$ diz ter buscado este conhecimento na pós-graduação. Quanto à realização de um curso direcionado ao laser, apenas $16 \%$ relata ter buscado, porém a minoria com $80 \%$ diz que não.

À partir deste trabalho de pesquisa, pode-se observar que o laser está se tornando cada dia mais utilizado nos consultórios odontológicos, porém, o conhecimento adequado de suas aplicações ainda é pouco enfatizado. Este recurso possui diversas indicações, as quais não são exploradas pelos dentistas pela falta do conhecimento das suas características.

\section{CONCLUSÃO}

Um baixo percentual de alunos do curso de Odontologia demonstrou ter conhecimento sobre a laserterapia. Também verificou-se que existe pouca transmissão de informação sobre este assunto na graduação. Com relação aos professores, já profissionais da área de saúde, houve também um baixo nível de conhecimento sobre o laser e seus recursos.

Estes resultados demonstram a necessidade de implementação da literatura e transmissão de conhecimento sobre o laser, tanto na graduação de
Odontologia quanto na pós-graduação, já que este recurso está tendo resultados positivos no consultório odontológico e tem sido cada vez mais implementado no cotidiano das clinicas.

\section{REFERÊNCIAS}

1. Brugnera Junior A. Atlas de laserterapia aplicada à clínica odontológica. São Paulo: Santos; 2003.

2. Dias V, Lima G, Silva G. Aplicações do laser de baixa intensidade na odontologia. [Apresentação na XIII Encontro Latino Americano de Iniciação Científica e

IX Encontro Latino Americano de Pós-Graduação, Universidade do Vale do Paraíba; 2O11].

3. Mendonça G. Efeitos terapêuticos do laser de baixa potência na regeneração de nervos periféricos. Goiânia; 2009. Trabalho apresentado à disciplina Seminários Aplicados do Programa de Pós-Graduação em Ciência Animal da Escola de Veterinária da Universidade Federal de Goiás.

4. Andrade A, Lima C, Albuquerque A. Efeitos do laser terapêutico no processo de cicatrização das queimaduras. Rev. bras. Queimaduras, Pernambuco. 2010; 9(1):21-30.

5. Henriques A, Maia A, Cimões R, Castro J. A laserterapia na odontologia: propriedades, indicações e aspectos atuais. Odontologia. clín.cient. 2008; 7(3):197-200.

6. Oliveira M; Souza A. Efeitos do laser de baixa potência $(685 \mathrm{~nm})$ na cicatrização de feridas cutâneas. Mafra: Universidade do Contestado, Campus Mafra; 2011.

7. Prockt A, Takahashi A, Pagnoncelli R. Uso de terapia com laser de baixa intensidade na cirurgia bucomaxilofacial. Rev Port Estomatol Med Dent Cir Maxilofac. 2008; 49(4):247-55.

8. Belotti F. Laser na Odontologia. São Paulo: abc da saúde; 2008. [Acesso em 21 de set. de 2011]. Disponível em http://www.abcdasaude.com.br/ artigo.php?685\&-laser-na-odontologia.

9. Paiva P, Nunes E, Silveira F, Cortes M. Aplicação clínica do laser em endodontia. RFO. 2007;12(2):84-8.

1O. Pinheiro ALB, Limeira Junior FA, Ramalho LMP, Ponzi EAC, Gerbi MEMM, Marzola C. Effect of Low 
Level Laser Therapy on the Repair of Bone Defects Grafted with Inorganic Bovine Bone. Braz. Dent. J.2003;14(3):177-81.

11. Pinheiro ALB, Oliveira MG, Martins PPM, Ramalho LMP, Oliveira MAM, Novaes Júnior $A$, et al. Biomodulatory effects of LLLT on bone regeneration. Laser Therapy. 2001;13:73-9.

12. Deterling L, Matias A, Prado E, Leitão R, Barone $M$, Ferreira $C$. Benefícios do laser de baixa potência no pós cirúrgico de cirurgia plástica. Revista Augustus. 2010; 14( 29): 45-53.
13. Neves L, Silva C, Henriques J, Cançado R, Henriques R, Janson G. A utilização do laser em Ortodontia. R Dental Press Ortodon Ortop Facial. Maringá. 2005; 10(5):149-56.

14. Rocha J. Terapia laser, cicatrização tecidual e angiogenese. RBPS. 2004; 17(1):44-48.

15. Ribeiro ECO. Novos espações sociais de aprendizagem e difusão do conhecimento. Caderno LCE. 1999.

\section{APÊNDICE A - QUESTIONÁRIO ALUNO}

Entrevista No

Data Hora

Entrevistador

Tempo de entrevista

Nome:

(opcional)

\section{IDENTIFICAÇÃO}

(1) Idade:

(2) Sexo: Masculino( ) Feminino( )

(3) Estado civil: Solteiro( ) Casado( ) Outro( )

Qual?

(4) Semestre do curso de Odontologia:

(5) Ano de ingresso:

(6) Pretende seguir alguma especialidade após formatura?

Sim( ) Não( )

(7) Qual?

(8) Já esteve em algum congresso de Odontologia?

\section{ATITUDES E CONHECIMENTOS RELACIONADOS AO LASER}

(9) Sabe o que é LASER?

$\operatorname{Sim}($ ) Não( )

(10) Possui aparelho de LASER particular?

$\operatorname{Sim}($ ) Não( )

(11) ( ) Cirúrgico ( ) Terapêutico

(12) Possui aparelho de Laser na IES (Instituição de Ensino Superior)?

Sim( ) Não( ) Não sei ( ) 
(13) ( ) Cirúrgico ( ) Terapêutico

(14) Você tem acesso ao Laser?

$$
\operatorname{Sim}(\text { ) Não( ) }
$$

(15) LASER é:
a) Luz
b) Luz Halógena
c) Luz Vermelha
d) Luz polarizada
e) Amplificação da luz por emissão estimulada de radiação

(16) Você teve alguma aula deste assunto na sua graduação?

$$
\operatorname{Sim} \text { ( ) Não( ) }
$$

(17) Já fez algum curso direcionado ao Laser na área de saúde?

$$
\operatorname{Sim}(\text { ) Não( ) }
$$

(18) Tem interesse em fazer algum curso na área de Laser?

$$
\operatorname{Sim}(\text { ) Não( ) }
$$

(19) Teve acesso a alguma bibliografia relacionada a área de Laser em Odontologia?

$\operatorname{Sim}($ ) Não( )

(20) Se afirmativo? ( )Periódicos ( ) Livros?

(21) Conhece as características que diferenciam o Laser cirúrgico do Laser terapêutico? $\operatorname{Sim}($ ) Não( )

(22) Conhece as normas de Biossegurança para utilização do Laser? $\operatorname{Sim}($ ) Não( )

(23) Dentre as situações clínicas abaixo, quais as indicações para Laserterapia?
( ) Mucosite
( ) Herpes Labial
( ) Cândida
( ) Leucoplasia
( ) Carcinoma
( ) Quelite Angular
( ) Dor em pós-operatorio
( ) Abcesso
( ) Gengivite
( ) Periodontite
( ) Clareamento
( ) Mucocele
( ) Sensibilidade dentária
( ) Paralisia facial
( ) DTM
( ) Parestesia
( )Fibroma 
(24) Dentre as situações clínicas abaixo, quais as indicações do Laser cirúrgico?

( ) Mucosite

( ) Herpes Labial

( ) Cândida

( ) Leucoplasia

( ) Carcinoma

( ) Quelite Angular

( ) Dor em pós-operatorio

( ) Abcesso

( ) Gengivite

( ) Periodontite

( ) Clareamento

( ) Mucocele

( ) Sensibilidade dentária

( ) Paralisia facial

( ) DTM

( ) Parestesia

( )Fibroma

(25) Aplica-se Laser em grávidas?

Sim( ) Não ( ) Não sei ( )

(26) Aplica-se Laser em pacientes com marcapasso?

$\operatorname{Sim}($ ) Não ( ) Não sei ( )

\section{AVALIAÇÃO DO QUESTIONÁRIO}

\section{Quanto a este questionário:}

Clareza dos questionamentos ( ) Ruim ( ) Regular ( )Bom ( ) Ótimo Rapidez

( ) Ruim ( ) Regular ( )Bom ( ) Ótimo

Facilidade de resposta

( ) Ruim ( ) Regular ( )Bom ( ) Ótimo 


\section{APÊNDICE B - QUESTIONÁRIO PROFESSOR}

Entrevista No

Data Hora

Entrevistador

Tempo de entrevista

Nome:

(opcional)

\section{IDENTIFICAÇÃO}

(1) Idade:

(2) Sexo: Masculino( ) Feminino( )

(3) Estado civil: Solteiro( ) Casado( ) Outro( )

Qual?...

(4) Tempo de profissão na odontologia:

(5) Escolaridade:

[ ] Graduação

[ ] Especialização

Área:

[ ] concluída

[ ] em andamento

[ ] Mestrado

Área:

[ ] concluído

[ ] em andamento

[ ] Doutorado

Área:

[ ] concluído

[ ] em andamento

(6) Ano que terminará:

(7) Leciona na: ( ) Graduação ( ) Pós-graduação

(8) Leciona na Pós-graduação: ( ) latu senso ( ) strito senso

(9) Leciona para quais semestres da graduação?

(10) Leciona disciplina: ( ) clínica/cirúrgica ( ) laboratorial

(11) Média de alunos por semestre:

(12) Há quanto tempo leciona?

(13) E somente nesta instituição?

$\operatorname{Sim}($ ) Não( ).

(14) Quantas instituições?

(15) Vínculo: ( ) Professor substituto ( ) Professor efetivo

(16) Especialidade ou área de atuação:

(17) Trabalha em outra área/especialidade?

$\operatorname{Sim}($ ) Não( ) Qual?

(18) Trabalha em clínica particular?

$\operatorname{Sim}($ ) Não( ) 


\section{ATITUDES E CONHECIMENTOS RELACIONADOS AO LASER}

(19) Sabe o que é LASER? Sim( ) Não( )

(20) Possui aparelho de LASER particular?

$\operatorname{Sim}($ ) Não( )

(21) ( ) Cirúrgico ( ) Terapêutico

(22) Possui aparelho de Laser na IES(Instituição de Ensino Superior)?

$\operatorname{Sim}($ ) Não( ) Não sei ( )

(23) ( ) Cirúrgico ( ) Terapêutico

(24) Você tem acesso ao Laser? Sim( ) Não( )

(25) LASER é:
a) Luz
b) Luz Halógena
c) Luz Vermelha
d) Luz polarizada
e) Amplificação da luz por emissão estimulada de radiação

(26) Você teve esse conhecimento introduzido durante a sua graduação?

$\operatorname{Sim}($ ) Não( )

(27) Você teve esse conhecimento introduzido durante a sua pós-graduação?

$\operatorname{Sim}($ ) Não( )

(28) Já fez algum curso direcionado ao Laser na área de saúde? Sim( ) Não( )

(29) Tem interesse em fazer algum curso na área de Laser? Sim( ) Não( )

(30) Teve acesso a alguma bibliografia relacionada a área de Laser em Odontologia? Sim( ) Não( )

(31) Se afirmativo? ( )Periódicos ( )Livros?

(32) Utiliza o Laser na sua vida clínica? Sim( ) Não( )

(33) Conhece as características que diferenciam o Laser cirúrgico do Laser terapêutico? $\operatorname{Sim}($ ) Não( )

(34) Conhece as normas de Biossegurança para utilização do Laser? Sim( ) Não( )

(35) Dentre as situações clínicas abaixo, quais as indicações para Laserterapia?

( ) Mucosite

( ) Herpes Labial

( ) Cândida

( ) Leucoplasia

( ) Carcinoma

( ) Quelite Angular

( ) Dor em pós-operatorio

( ) Abcesso

( ) Gengivite

( ) Periodontite 
( ) Clareamento

( ) Mucocele

( ) Sensibilidade dentária

( ) Paralisia facial

( ) DTM

( ) Parestesia

( )Fibroma

(36) Dentre as situações clínicas abaixo, quais as indicações do Laser cirúrgico?

( ) Mucosite

( ) Herpes Labial

( ) Cândida

( ) Leucoplasia

( ) Carcinoma

( ) Quelite Angular

( ) Dor em pós-operatorio

( ) Abcesso

( ) Gengivite

( ) Periodontite

( ) Clareamento

( ) Mucocele

( ) Sensibilidade dentária

( ) Paralisia facial

( ) DTM

( ) Parestesia

( )Fibroma

(37) Aplica-se Laser em grávidas?

$\operatorname{Sim}($ ) Não ( ) Não sei ( )

(38) Aplica-se Laser em pacientes com marcapasso?

$\operatorname{Sim}($ ) Não ( ) Não sei ( )

\section{SE USUÁRIO DO LASER}

(39) O Laser mudou sua conduta clínica? Sim( ) Não ( ) Não sei ( )

(40) Faz clareamento a Laser na sua prática clínica? Sim( ) Não ( )

(41) Se sim, qual dos Lasers abaixo?
a) Argônio
b) Criptônio
c) LED
d) Diodo 
(42) O valor cobrado no clareamento a Laser é o mesmo cobrado no clareamento normal? $\operatorname{Sim}($ ) Não ( )

(43) Na sua experiência e observação nota diferentes resultados clínicos entre o clareamento a Laser e o convencional? Sim( ) Não ( ) Não sei ( )

(44) Polimeriza resinas compostas com Laser? Sim( ) Não ( )

(45) Se sim, qual dos Lasers abaixo?
a) Argônio
b) Criptônio
c) LED
d) Diodo

(46) Faz Cirurgia com LASER? Sim( ) Não ( )

(47) Se sim, qual dos Lasers abaixo?
a) Diodo
b) Er:YAG
c) Nd:YAG
d) $\mathrm{CO}_{2}$

\section{AVALIAÇÃO DO QUESTIONÁRIO}

\section{Quanto a este questionário:}

Clareza dos questionamentos ( ) Ruim ( ) Regular ( ) Bom ( ) Ótimo

Rapidez

( ) Ruim ( ) Regular ( ) Bom ( ) Ótimo

Facilidade de resposta

( ) Ruim ( ) Regular ( ) Bom ( ) Ótimo 